\title{
Overview of Chinese Characters Unique to Korea
}

\author{
YOON Chang-joon (Corresponding author) \\ Professor of Department of Chinese Studies, \\ Keimyung University, South Korea \\ E-mail: cjyoon@kmu.ac.kr
}

\begin{abstract}
Received: February 5, 2021 Accepted: March 16, 2021 Published: March 18, 2021
doi:10.5296/ijch.v8i1.18284 URL: https://doi.org/10.5296/ijch.v8i1.18284
\end{abstract}

\begin{abstract}
In this paper, the situation of Chinese characters unique to Korea made in Korea and used only in Korea was analyzed. Such a study will provide major information on how Korean ancestors used their unique Chinese characters and what contents the unique Chinese characters were intended to contain. This study is also expected to help the understanding of how Chinese characters were used in the different language environments for Korean and Chinese with different language systems from each other and how those meanings unique to Korea that could not be expressed in Chinese characters were written.
\end{abstract}

Keywords: Korea, Korean-Chinese character, source

\section{Introduction}

Language was born as mankind began to exist for the first time, and mankind became to invent characters to overcome the temporal and spatial constraints of language. After characters were invented, mankind became to express their thoughts and emotions and record a lot of information in characters.

Korean characters were born in Korea only during the Joseon Dynasty period when quite some time had passed after the beginning of civilization. The characters currently used in Korea, that is, 'Hangul', are phonograms made by King Sejong the Great, the fourth king of the Joseon Dynasty through studies for a long period of time with the scholars of the Hall of Worthies (Jiphyeonjeon). Hunminjeongum (訓民正音;Korean scripts) was created in 1443 and promulgated three years later. (Note 1) Later, Ju Si-gyeong changed the name 'Hunminjeongeum' into 'Hangul', which contains the meaning 'Korean characters' along with the meanings 'the greatest characters' and 'the only good characters'. 
So why did King Sejong make 'Hangul'?

Prior to the creation of Hangul, Korean ancestors wrote Korean language in Chinese characters. However, because the language systems of Korean and Chinese were different, there were limitations in writing Korean vocabularies in Chinese characters, which are the characters of China. King Sejong the Great, who created 'Hunminjeongum', stated the reason why he created 'Hunminjeongum' as follows, 'Ignorant people cannot communicate their intentions even when they want to tell something. Since I feel sorry for that, I newly made twenty-eight characters. I hope that people can easily learn them and conveniently use them every day." That is, in order to record Korean in Chinese characters, Chinese characters had to be studied a lot and it was very difficult for general ordinary people except for some people in the class with power at that time.

Then, how did Korean ancestors wrote their language before 'Hangul' was created?

Among the vocabularies contained in the [ Korean Dictionary] compiled by the Korean Language Society in 1957, 54.5\% are loanwords and among the loanwords, $84.4 \%$ are Sino-Korean words.(Cho, 1992) In addition, according to the [Survey of the frequencies of use of Korean vocabularies], out of 56,096 words, Sino-Korean words were 39,563 words, accounting for $70 \%$.( Lee, 1974)

Sino-Korean words refer to those vocabularies in which individual syllables that constitute vocabulary terms are identical to the reading sounds of the relevant Chinese characters. (Song, 1992) These words are used in Korean language without being recognized as loanwords because they have been used in Korea for long periods of time.

The reason why so many Sino-Korean words are used in Korean language is that Chinese has been the most familiar foreign language to us from very long ago, and the history of introduction of Chinese characters, the Chinese record system, is also very long. Of course, since Chinese characters are a product of culture and culture should be regarded to have been gradually propagated, it is very difficult to determine the precise time of introduction of Chinese characters at present. However, the time of introduction of Chinese characters can be estimated through the history of exchanges between Korea and China.

First, many Chinese characters might have been introduced after Han Wu-Ti installed Four Commanderies of Han in the Korean peninsula region in B.C. 108. In addition, since the Three Kingdoms of Korea; Goguryeo, Baekje, and Silla exchanged with Chinese dynasties thereafter beginning from Qin Dynasty, followed by Six Dynasties, Sui Dynasty, and Tang Dynasty in order of precedence between the fourth century to the sixth century through overland routes and sea routes, it can be assumed that Chinese characters were continuously introduced into the Korean peninsula in the process of such exchanges.

The about 1,800 Chinese characters inscribed in the epitaph of King Gwanggaeto the great of Goguryeo (414), the record in [Shiji (史記)] indicating that Goh Heung (高興) of Baekje 
wrote [Shūjì(書記)] using Chinese characters for the first time, and the fact that Jijeung Maripgan(智證麻立干: 500 514) of Silla accepted the province/county/prefecture system (州郡縣制) of China and changed the names such as Nisageum (尼師今) and Maripgan (麻立干) into the Chinese name king (王) are evidences that in the Korean peninsula, the ruling class not only used Chinese characters widely but also adopted Chinese classics as written language latest by around the sixth century.(Choi, 1995)

In addition, there is a claim that Chinese characters were first introduced into Korea around B.C.220, which was during the reign of Qin Shi Huang, based on a stone engraved with the Chinese characters ‘徐市過此'. However, this is only a legend without any ground to prove the fact. (Lee, 2000)

As such, through the process of close cultural contact with China, Chinese became the most familiar foreign language to us from the very early days and along with the borrowing of Chinese characters, Sino-Korean words were also introduced massively. (Kim, 1989)

However, over long periods of time, Chinese characters have been fixed into Sino-Korean words, which match unique words in the vocabulary system of Korean language, while undergoing the processes of addition and elimination in terms of forms, meanings, and parts of speech due to the intrinsic and extrinsic constraints of Korean language to show certain common features with and differences from the original language. (Choi, 2001)

In particular, Korean vocabularies included many vocabularies unique to Korea that could not be written in Chinese characters. Prior to the creation of Hangul, Chinese characters unique to Korea that would be used only in Korea were necessary to write such vocabularies.

\section{Emergence of Chinese characters unique to Korea, Korean-Chinese characters (國字, guo zi)}

As everybody knows, Chinese characters have a very long history. During the history of Chinese characters, which began with inscriptions on bones and tortoise carapaces, the same character system has been maintained although Chinese characters underwent many changes in the shapes of characters until the current simplified characters were made. Chinese characters, which originated in China, have greatly contributed to the recording of the history of China and have had great effects on neighboring countries.

In particular, Chinese characters have had great effects on Korea too. First, Chinese characters had been used to write Korean language before the Korean characters, that is, Hangul, were created, and this played important roles in various aspects of Korean society. Second, new Chinese characters that were not in Chinese characters in China were necessary to write vocabularies unique to Korea because there were cases where no Chinese character corresponded to Korean vocabularies since the language systems of Korean and Chinese were different. To write such vocabularies unique to Korea, Korean ancestors attempted to make new Chinese character combinations using existing Chinese characters, and through such 
attempts, they created new Chinese characters consisting of existing Chinese characters. Although such Chinese characters look similar to Chinese characters in China at first glance, they are Chinese characters unique to Korea and not available in dictionaries in China. In this paper, these Chinese characters unique to Korea will be briefly referred to as 'Korean-Chinese characters (國字)'. The Korean-Chinese characters were continuously used to write vocabularies unique to Korea even after the creation of Hunminjeongeum in 1443.

Currently, 199 Korean-Chinese characters can be found in ancient literature of Korea. Although the number is not large, such Korean-Chinese characters are precious materials that inform how Korean ancestors wrote vocabularies unique to Korea using Chinese characters, and are historical materials informing how meanings were delivered using Chinese characters in different language systems such as Korean and Chinese. Korean-Chinese characters can be divided into several types according to the ways to constitute characters. In this paper, several characters that can indicate the characteristics of Korean-Chinese characters the most clearly will be examined while dividing them into different types according to the ways to constitute characters.

\section{Analyses by Type}

1) Korean-Chinese characters made by combining the meanings of Chinese characters and Hunminjeongeum

The Korean-Chinese characters belonging to this type are characters made by combining the meanings of Chinese characters and Hunminjeongeum. An example is as follows.

\section{夜 $[$ bem $]$}

This character is a Korean-Chinese character made by vertically combining the Chinese character '夜', and ' $\square$ ', which is used as a final consonant in Hunminjeongeum. The meaning of the character is 'snake', and the sound of the character is [bem]. [bem] in Korean means '蛇' in Chinese.

Korean ancestors regarded that snakes were mostly active at night. Therefore, they used the Chinese character '夜', which means 'night'. In addition, in order to distinguish the meaning from the original meaning of '夜' and highlight the meaning 'snake', they added ' $\square$ ' of Hunminjeongeum, which represents [-m], the final consonant of the Korean vocabulary '뱀'

2) Korean-Chinese characters made by combining the Korean reading sounds of Chinese characters and Hunminjeongeum

The Korean-Chinese characters belonging to this type are new Korean-Chinese characters made by combining Chinese characters indicating the pronunciations of vocabularies unique to Korea and Hunminjeongeum in order to write vocabularies unique to Korea. An example is as follows. 
㕺 $[$ gak $]$

This is a Korean-Chinese character made by vertically combining the Chinese character 加, and ' $\neg$ ', which is used as a final consonant in Hunminjeongeum. Although the meaning of the character is not clear, the sound of this character is [gak]. The Chinese character 加 was used to write vocabularies unique to Korea with the pronunciation of [gak]. Although the Chinese pronunciation of 加 is [jia ], the reading sound of 加 in Korea was [ga] . In addition, ' $\neg$ ', which is used as a final consonant in Hunminjeongeum, was added to the bottom of 加to indicate the final consonant $[-\mathrm{k}]$. In this case the meaning of the character has nothing to do with ' $\neg$ ' and ' $\neg$ ' just indicates the pronunciation of the character.

3) Korean-Chinese characters made in the phonetic method among the six writing methods

The phonetic method is one of the six writing methods, which are the six methods of making Chinese characters, which overcame the limitations of ideograms and added phonetic components to characters. Among Korean-Chinese characters, those that were made in this phonetic method are seen. An example is as follows.

楛 [go]

This Korean-Chinese character was made by combining the shape symbol $\square$ and the sound symbol 苦. The meaning is similar to that of the Chinese exclamation “哎呀”(damn). However, the pronunciation in the vocabulary unique to Korea was different from that of Chinese. Therefore, a new character was necessary to write the vocabulary unique to Korea. Therefore, a character indicating the vocabulary unique to Korea pronounced as [go] meaning admiration was made. First, to indicate the meaning of 'admiration', 口, which is one of Chinese characters used in relation to 'mouth' was used as a part of the character. In addition, since the pronunciation is similar to the Korean reading sound of the Chinese character 苦, 苦 was used as the sound symbol of this character to indicate the pronunciation of this character. Whereas the Chinese pronunciation of 苦 is $[\mathrm{ku}]$, the Korean reading sound of it is [go].

4) Korean-Chinese characters made by combining the Korean reading sounds of Chinese characters.

The Korean-Chinese characters belonging to this type are made by combining Korean reading sounds of Chinese characters to indicate the pronunciations of vocabularies unique to Korea. That is, Chinese characters were combined based on Korean reading sounds of them instead of their Chinese pronunciations. In the case of these Korean-Chinese characters, the meanings of the characters that constitute the Korean-Chinese characters have nothing to do with the Korean-Chinese characters. They were simply used for their reading sounds. Examples are as follows.

旮[gul] 
This is a Korean-Chinese character made by vertically combining 九 and 乙. Although the meaning is not clear, the pronunciation of this character is [gul]. That is, the Chinese characters 九 and 乙 were combined to write vocabularies unique to Korea pronounced as [gul]. Whereas the Chinese pronunciation of 九 is [jiu ], the Korean reading sound of it is [gu]. In addition, the Chinese character 乙 was used to indicate the final consonant of the character and in this case, the Chinese pronunciation [y̌l] of 乙 was not borrowed but only the pronunciation [-1] of the final consonant of the Korean reading sound of 乙 was employed. This enabled the writing of the vocabularies unique to Korea pronounced as [gul].

去[sal]

This is a Korean-Chinese character made by vertically combining 土 and 乙. Although the meaning is not clear, the pronunciation of this character is [sal]. The Chinese characters 士 and 乙 were combined to write vocabularies unique to Korea pronounced as [sal]. Whereas the Chinese pronunciation of \pm is [shì ], the Korean reading sound of it is [sa]. In addition, the Chinese character 乙 was used to indicate the final consonant of the character and in this case, the Chinese pronunciation [y̌l] of 乙 was not borrowed but only the pronunciation [-1] of the final consonant of the Korean reading sound of 乙 was employed. This enabled the writing of the vocabularies unique to Korea pronounced as [sal].

昰[hal]

This is a Korean-Chinese character made by vertically combining 下 and 乙. Although the meaning is not clear, the pronunciation of this character is [hal]. The Chinese characters 下 and 乙 were combined to write vocabularies unique to Korea pronounced as [hal]. Whereas the Chinese pronunciation of $下$ is [xià ], the Korean reading sound of it is [ha]. In addition, the Chinese character 乙 was used to indicate the final consonant of the character and in this case, the Chinese pronunciation [y̌l] of 乙 was not borrowed but only the pronunciation [-1] of the final consonant of the Korean reading sound of $乙$ was employed. This enabled the writing of the vocabularies unique to Korea pronounced as [hal].

吾[ol]

This is a Korean-Chinese character made by vertically combining 五 and 乙. Although the meaning is not clear, the pronunciation of this character is [ol]. The Chinese characters 五 and 乙 were combined to write vocabularies unique to Korea pronounced as [hal]. Whereas the Chinese pronunciation of 五 is [wǔ], the Korean reading sound of it is [o]. In addition, the Chinese character 乙 was used to indicate the final consonant of the character and in this case, the Chinese pronunciation [y̌̃] of 乙 was not borrowed but only the pronunciation [-1] of the final consonant of the Korean reading sound of $乙$ was employed. This enabled the writing of the vocabularies unique to Korea pronounced as [ol]. 
5) Korean-Chinese characters made using pseudo characters for sounds

Pseudo characters for sounds are Chinese characters used for their sounds regardless of their original meaning. In particular, pseudo characters for sounds were widely used to indicate the grammatical forms such as postpositional particles and endings of words. For instance, postpositional particles “-을(eul), -도(do), -뿐(ppun)” could be written as “乙，刀，分”, respectively, and endings of words “-고(go), -나(na), -면(myeon)” could be written as “古, 那, 面”, respectively. An example of Korean-Chinese characters made using pseudo characters for sounds is as follows.

始 $[$ bi-lot]

This is a Korean-Chinese character made by vertically combining 始 and 叱. The meaning of the character is 'originate' and the pronunciation is [bi-lot]. That is, the pronunciation of a vocabulary unique to Korea meaning 'originate' was [bi-lot] and since a character to write the vocabulary was necessary, the Chinese character '始' meaning 'originate' and 吨 [-t] indicating the pronunciation, that is, the final consonant of this vocabulary were combined to make the relevant Korean-Chinese character.

\section{Conclusion}

Chinese characters were made to record Chinese language. The history of such Chinese characters is very long and Chinese characters have affected many surrounding countries for long periods of time. Korean ancestors also used Chinese characters to record histories and facts in many fields until the creation of Hunminjeongeum. However, since the language systems of Chinese and Korean were different and the vocabularies used were also different, new characters that can be used to write vocabularies unique to Korea, which could not be written in Chinese characters, became to be necessary. Therefore, Korean ancestors made new Chinese characters, that is, Korean-Chinese characters used only in Korea, using the existing Chinese characters to record vocabularies unique to Korea.

Major methods in which the Korean-Chinese characters were made were examined with examples and as a result, it could be seen that the Korean-Chinese characters could be divided into five types; that are, Korean-Chinese characters made by combining the meanings of Chinese characters and Hunminjeongeum, those made by combining the Korean reading sounds of Chinese characters and Hunminjeongeum, those made in the phonetic method among the six writing methods, those made by combining the Korean reading sounds of Chinese characters, and those made using pseudo characters for sounds.

\section{References}

Bae, J.-S. (2003). Comparative surveys of Sino-Korean words in Korea, China, and Japan that appeared in information processing terms. 中國言語研究, 17, the Chinese Linguistic Society of Korea.

Byeon, H.-W., \& Kang, P.-I. (2003). New attack on Chinese. basic part. Seoul: Darakwon. 
Cho, S.-Y. (1992). A Study on Naturalized Words from Sino-Korean words. Seoul: Research Institute of Korean Studies, Korea University.

Choi, G.D. (2001). A comparative study of modern Chinese and Sino-Korean words in Korea. Osan: Publishing Department, Hanshin University.

Choi, H.-I. (2000). Controversies over 'Korean-Chinese characters in Korean' in the late $19^{\text {th }}$ century. Graduate School, Yonsei University.

Choi, Y.-A. (1995). What is Chinese? Seoul: Tongnamu.

Jeong, Y.-C. (1998). Regarding the compilation of Chinese textbooks. Foreign Language Education, 4(1), The Korea Association of Foreign Languages Education.

Kim, G.-H. (1989). Matching phenomena between unique words and Sino-Korean words. [國語學叢書]16, Seoul: Top Publishing Co.

Kim, G.-S. (1986). A study on textbooks for Korean as a foreign language, master's thesis. Graduate School, Yonsei University.

Lee, G.-G. (2000). I am curious about Chinese characters. Seoul: Hakminsa.

Lee, Y.-J. (1974). A Study on Sino-Korean Words in Korea. Seoul: Samyeongsa.

Nam, G.W. (1970). Various Problems of Korean-Chinese Characters in Korean. Seoul: 一潮閣.

Park, Y.-S. (1997). Theory of bilingual/multilingual education. Seoul: Hanshin Munhwasa.

Song, G-J. (1992). Structure of Sino-Korean Words in Modern Korea. [韓國語文], Seoul: The Academy of Korean Studies.

Yun, E.-H. (1982). A comparative study of Chinese character education in Korea, China, and Japan. [語文研究] 10(1), The Society for Korean Language \& Literary Research.

\section{Note}

Note 1. 'Hunminjeongeum' means 'the right sounds to teach the people', but it is also the name of the guidebook for Hunminjeongeum published in 1446. The guidebook contains the purpose of creation of Hunminjeongum, the preface written by King Sejong, the principle of making Hangul, and detailed explanations with examples. It is currently the National Treasure No. 70 of Korea and designated as a UNESCO Memory of the World. 


\section{Copyrights}

Copyright for this article is retained by the author(s), with first publication rights granted to the journal.

This is an open-access article distributed under the terms and conditions of the Creative Commons Attribution license (http://creativecommons.org/licenses/by/4.0/) 